\title{
Estudos em rede sobre os princípios da formação docente na contemporaneidade: uma análise da realidade na UP/Moçambique
}

\author{
Suzete Lourenço Buque ${ }^{1}$
}

\begin{abstract}
RESUMO
Este artigo tem como objetivo analisar os princípios gerais que orientam a formação de professores na fase contemporânea. Buscamos refletir sobre o como eles permeiam a formação de professores, buscando identificar e compreender se há aproximações com os princípios que orientam a formação de professores na Universidade Pedagógica de Moçambique (UP). A reflexão baseou-se na pesquisa documental e na experiência pessoal, como docente da mesma instituição. A leitura de documentos orientadores aponta para a existência de aproximações, mas também divergências. O desafio está na correta interpretação e na criação de um contexto que favoreça a aplicação dos princípios comuns, sobretudo no que se refere a concepção de educação que cada professor formador defende.
\end{abstract}

PALAVRAS-CHAVE: Estudos em rede. Princípios da formação. Formação de professores.

Network studies on the principles of contemporary teacher education: an analysis of the influences on teacher education at UP/Mozambique

\begin{abstract}
This article focuses on the principles that guide the training of teachers in the contemporary phase. This aims to reflect on the principles that underlie the Training teachers in contemporary phase, seeking to identify the approaches that exist with some of the principles that guide
\end{abstract}

\footnotetext{
${ }^{1}$ Doutora em Geografia. Docente do Departamento de Geografia, Universidade Pedagógica. Maputo. Moçambique. África Oriental. Orcid: https://orcid.org/0000-0002-6541-6651. E-mail: suzete1965@ yahoo.com.br.
} 
the training of teachers at the Pedagogical University of Mozambique (UP). Reading some documents guiding points to the existence of some approximations, however the challenge lies in correctly interpreting and creating an environment that encourages their implementation.

KEYWORDS: Network studies. Principles of training. Teacher training.

Estudios en red sobre los principios de la formación docente contemporánea: un análisis de las influencias en la formación docente en UP / Mozambique

\section{RESUMEN}

Este artículo tiene como objetivo analizar los principios generales que orientan la formación del profesorado en la fase contemporánea. Buscamos reflexionar sobre cómo permean la formación del profesorado, buscando identificar y comprender si existen enfoques con los principios que orientan la formación del profesorado en la Universidad Pedagógica de Mozambique (UP). La reflexión se basó en la investigación documental y la experiencia personal como docente de la misma institución. La lectura de documentos de orientación apunta a la existencia de similitudes, pero también divergencias. El desafío radica en la correcta interpretación y creación de un contexto que favorezca la aplicación de principios comunes, especialmente en lo que respecta al concepto de educación que defiende cada formador de docentes.

PALABRAS CLAVE: Estudios de redes. Principios de formación. Formación de profesores.

\section{Introdução}

Os estudos em redes de pesquisas favorecem o debate e as interlocuções, o que gera novas interpretações de temas importantes para a formação de professores ${ }^{2}$. Como explicitaram Magalhães, Souza e Argüello (2022), auxiliam na conjunção das interlocuções coletivas, o que

\footnotetext{
${ }^{2}$ Esta pesquisa está vinculada à REDECENTRO - Rede de Pesquisadores sobre o Professor da Região Centro-Oeste/Brasil.
} 
acaba por consolidar reflexões teóricas e epistemológicas que ajude na superação de um pensamento linear, baseado, por exemplo, no senso comum. Como explicam os autores, o pensamento linear pode ser bastante comum entre pesquisadores(as) - iniciantes, alunos(as) de graduação, de pós-graduação, bolsistas etc., mostrando dificuldades que os mesmos se deparam no processo formativo. A associação em redes de pesquisas favorece, assim, a aprendizagem de váriados referenciais teóricos ou conceituais, ampliação da experiência na elaboração de pesquisas, particiapção em contextos de debates e interlocuções sobre variados objetos de estudo, partilha de saberes, o que influencia, ao final, a própria produção do conhecimento gerida pela rede de pesquisadores (MAGALHÃES; SOUZA; ARGÜELLO, 2022).

É possível afirmar que, a partir da experiência como pesquisadora integrada a Redecentro (Rede de Pesquisadores sobre o professor na região Centro-Oeste/Brasil), amplia-se a capacidade de pesquisa, bem como a interlocução de objetos de estudos, como é o caso da centralidade da análise apresentada nesse artigo que se ocupa de destacar os princípios da formação de professores na contemporaneidade e, a partir dos estudos coletivos em Rede, empreender a análise das influências dos mesmos na formação docente promovida na Universidade Pedagógica (UP) de Moçambique.

Os estudos em rede ajudam a compor a reflexão sobre princípios que devem orientar a formação de professores, e o como eles são sustentados por autores na contemporaneidade, tais como Zeichner (1998, 2011), Nóvoa (2009, 2010), Pimenta (2002), Sacristán (1999), Contreras (2003), e outros que, no conjunto, destacam o objetivo de encontrar caminhos que possam contribuir para a melhoria dos processos formativos.

Os princípios que serão destacados ainda seguem várias perspectivas epistemológicas - da prática ou da práxis (MAGALHÃES; SOUZA, 2019c), que acabam por influenciar, de certo modo, a concepção de programas de formação de professores em várias partes do mundo. E ainda, os diferentes 
princípios e ou orientações que influenciam a formação e professores ainda se filiam a diferentes paradigmas (SOUZA, 2012) que também acabem sustentando outras formas de perceber e explicar os fenômenos educativos, o que tem impacto também na formação de professores.

Autores como Zeichner (1998, 2011), Nóvoa (2009, 2010) e Pimenta (2002) são alguns dos teóricos que têm contribuído com as suas formulações para a concepção de novas propostas de formação de professores, baseados numa concepção crítica, com um enfoque na transformação e superação da situação atual. Apesar de todos serem filiados a uma abordagem crítica, cada um desenvolve ao seu modo, a forma como entende que deve ser a formação de professores. Isso significa que enquanto membros de uma rede de pesquisa precisamos assumir, coletivamente, uma concepção crítica de formação de professores. Nesse sentido, destacamos aqui a concepção crítica que sustentamos a partir de Silva (2011) que

[...] entende a formação como atividade humana que transforma o mundo natural e social para fazer dele um mundo humano, sem que por outro lado essa atividade seja concebida com o caráter estritamente utilitário. Contém as dimensões do conhecer - da atividade teórica - e do transformar - a atividade prática, numa indissociação entre ambas: a teoria e a prática" (SILVA, 2011, p. 22).

Assim entendendo, na primeira parte do artigo será apresentado os princípios defendidos pelos autores que foram eleitos para orientar a reflexão - Zeichner (1998, 2011), Nóvoa (2009, 2010) e Pimenta (2002); na segunda, descreve-se as aproximações dos princípios defendidos pelos autores com aqueles que orientam a formação na Universidade Pedagógica de Moçambique (UP). Nas considerações finais apresentam-se reflexões coletivas desenvolvida pelo grupo da pesquisa, num movimento colaborativo que se ocupa de indicar algumas limitações para a aplicação dos princípios na formação e docente da UP-Moçambique. 


\section{Princípios e orientações que permeiam a formação de professores na fase contemporânea}

Nóvoa (2010) denuncia que na fase contemporânea há muito discurso sobre os professores. No entanto, verifica-se uma grande distância entre o discurso e a prática docente. Nóvoa considera que apesar dos discursos serem quase consensuais, em termos de princípios e medidas, faz-se necessário considerar e assegurar a aprendizagem docente e o desenvolvimento nesse sentido. Apesar de um suposto consenso discursivo, o autor aponta para a necessidade de:

[...] articulação de formação inicial, indução e formação em serviço numa perspectiva de aprendizagem ao longo da vida; atenção aos primeiros anos de exercício profissional e à inserção dos jovens professores nas escolas; valorização do professor reflexivo e de uma formação de professores baseada na investigação; importância das culturas colaborativas, do trabalho em equipa, do acompanhamento, da supervisão e da avaliação dos professores; etc. (NÓVOA, 2010. p. 15).

Ainda, segundo o autor, o discurso acima se tornou vulgar a partir de dois grupos: o primeiro, constituído por investigadores da área da formação de professores, das ciências da educação, das didáticas, das redes institucionais e dos grupos de trabalho diversos; o segundo, constituído por especialistas que fazem parte das grandes organizações internacionais ou que atuam como consultores à formação de professores. Nóvoa ainda explica que o primeiro grupo, nos últimos anos, produziu muitos textos que têm "como marca o conceito de professor reflexivo e que fez uma viragem no pensamento sobre professores e sua formação". (NÓVOA, 2010, p. 16). E o segundo, difundiu no plano mundial, práticas discursivas alicerçadas em argumentos comparados, devido ao seu conhecimento das redes internacionais. 
Importa salientar que nas medidas que Nóvoa aponta como consensuais, a que se refere ao conceito de professor reflexivo ${ }^{3}$, apesar de ter influenciado vários programas de formação de profissionais, foi alvo de críticas de diversos autores, devido a diferentes interpretações que são dadas ao conceito.

Pimenta (2002) considera que vários programas de formação de professores esvaziaram o conceito de professor reflexivo. Para ela, o limite deste conceito está no fato de restringir-se a uma reflexão individual em que as mudanças que se conseguem operar são imediatas, mas não conseguem alterar situações além da sala de aula. A autora afirma que é necessário considerar o conhecimento prático e teórico de forma dialética, mostrar que a teoria é importante nos processos formativos, reforçando que os saberes docentes não são constituídos apenas pela prática, mas nutridos também pelas teorias da educação.

Sobre o papel da teoria a autora ainda descreve,

A teoria como cultura objetiva é importante na formação docente, uma vez que, além de seu poder formativo, dota os sujeitos de pontos de vista variados para uma ação contextualizada. Os saberes teóricos propositivos se articulam, pois, aos saberes da prática, ao mesmo tempo ressignificando-os e sendo por eles ressignificados. O papel da teoria é oferecer aos professores perspectivas de análise para compreenderem os contextos históricos, sociais, culturais, organizacionais e de si mesmos como profissionais, nos quais se dá sua atividade docente, para neles intervir, transformando-os (PIMENTA, 2002, p. 26).

A citação de Pimenta (2002) alerta para o fato de não se valorizar apenas a prática em detrimento do conhecimento científico. Concorda-se com Pimenta, pois formação de professores não deve ser intrumental e tecnicista. Por essa razão, considera-se que o domínio de conhecimento científico pelos professores é importante quando articulado à prática e a

\footnotetext{
${ }^{3} \mathrm{O}$ conceito de professo reflexivo foi definido por Donald Schön. No entanto trata-se de uma concepção com algumas limitações, pois coloca o professor numa situação individualizada e pouco articulada com questões que vão além do praticismo da sala de aula.
} 
outros saberes. A autora sugere ainda que o termo intelectuais críticos reflexivo supere o de professor reflexivo.

Ainda sobre a crítica ao conceito de professor reflexivo, Liston e Zeicnher (2003) consideram que a reflexão é uma das dimensões do "acto pedagógico, mas, para sua compreensão aqueles que reflectem devem considerar as condições de produção desse trabalho". Assim entende-se que a reflexão não deve ser um ato individual, se faz necessário considerar as condições sociais, políticas e econômicas. Concorda-se com eles, pois o que acontece na sala de aulas é reflexo de toda uma conjuntura que acontece no meio envolvente.

Voltando à Nóvoa (2010) e sobre a sua preocupação relativa à distância que existe entre o discurso e a prática na formação de professores, e, posteriormente, na própria prática docente, ele questiona: Como fazer aquilo que dizemos que é preciso fazer?

$\mathrm{Na}$ tentativa de responder, apresenta algumas orientações tais como: i. Passar a formação de professores para dentro da profissão; ii. Promover novos modos de organização da profissão docente; iii. Reforçar a dimensão pessoal e a presença pública dos professores. Reconhece-se que existe uma relação dialética entre as três orientações, no entanto neste artigo, por razão de espaço e recorte, desenvolve-se a primeira por considerar que é um aspeto bastante evocado nas reformas dos programas de formação de professores no Brasil e em Moçambique.

A formação construída dentro da profissão, como descreveu Nóvoa (2010), consiste em dar maior destaque aos professores em exercício na formação dos seus colegas-futuros professores. Esse fato tem sido negligenciando por algumas instituições de formação de professores, o que inclui a Universidade Pedagógica de Moçambique. O autor, recorrendo a exemplo da formação de médicos, argumenta nos seguintes termos:

É preciso passar a formação de professores para dentro da profissão (...). Ao recorrer a esta expressão, quero sublinhar a necessidade de os professores terem um lugar predominante 
na formação dos seus colegas. Não haverá nenhuma mudança significativa se a "comunidade de formadores de professores e a "comunidade dos professores" não se tornarem mais permeáveis e imbricados. O exemplo dos médicos e dos hospitais escolares e o modo como a sua preparação está concebida nas fases de formação inicial, de indução e de formação em serviço talvez nos possa servir de inspiração" (NÓVOA, 2010, p. 18)

Nóvoa (2010) com este exemplo sobre a formação de médicos destacou a importância do envolvimento dos professores mais antigos, na formação dos mais jovens na profissão. Esta proposta julga-se que é concretizada numa situação em que existe comunicação/pareceria entre a universidade e a escola básica e ainda reconhecimento dos professores, como atores importantes na formação de futuros professores. O autor ainda se debruça sobre os desafios do trabalho do professor, na fase contemporânea, e aponta a necessidade da formação centrada nas práticas e na análise das práticas, como um elemento fundamental nos processos formativos.

Ele ainda descreve que a

[...] formação do professor é, por vezes, excessivamente teórica, outras vezes excessivamente metodológica, mas há um déficit de práticas, de refletir sobre as práticas, de trabalhar sobre as práticas, de saber como fazer. É desesperante ver certos professores que têm genuinamente uma enorme vontade de fazer de outro modo e não sabem como. Têm o corpo e a cabeça cheios de teoria, de livros, e teses, de autores, mas não sabem como aquilo tudo se transforma em prática, como aquilo tudo se organiza numa prática coerente. Por isso, tenho defendido, há muitos anos, a necessidade de uma formação centrada nas práticas e na análise dessas práticas (NÓVOA, 2009, p. 14)

Esta preposição de Nóvoa (2009) relaciona-se com aquela apresentada anteriormente que preconiza passar a formação de professores para dentro da profissão. Sua forma de conceber a formação de professores rompe com aquela em que a racionalidade técnica orientava a organização dos programas de formação de professores. 
Nesse sentido, a racionalidade técnica baseia-se numa epistemologia da prática derivada da filosofia positivista (MAGALHÃES, 2019a), ou seja, a racionalidade técnica diz que os profissionais são aqueles que solucionam problemas instrumentais, selecionando os meios técnicos mais apropriados para propósitos específicos. (SCHON, 2000, p. 15).

Nos programas de formação que se filiam à perspectiva da racionalidade técnica, portanto, a epistemologia da prática, dão um grande distanciamento entre a teoria e a prática. No entanto, como afirma Nóvoa, chama atenção ao fato de considerar que "não é a prática que é transformadora, mas sim a reflexão sobre a prática. "É capacidade de reflectirmos e analisarmos" (NÓVOA, 2009, p.15).

O alerta de Nóvoa mostra que não basta incluir a prática nos programas de formação de professores para garantir que os futuros professores consigam mais tarde lidar com a complexidade da profissão docente. Ele ainda reafirma a necessidade de trazer para a Universidade os problemas que são encontrados na escola, analisá-los de forma crítica e encontrar caminhos para a sua superação. Um dos caminhos que o autor coloca com a qual se concorda, é conceber a formação de professores baseada na investigação, que tenha como problemática a ação docente e o trabalho escolar. Ainda no que se relaciona com a investigação nos processos formativos, Pimenta (2002, p. 45) acrescenta que para uma sólida formação de professores é importante as universidades tomarem a pesquisa como um eixo fundamental na formação de professores.

Zeichner (2011) numa perspectiva diferente mas que, no entanto, coincide com alguns aspetos com Nóvoa (2009), destaca a importância de conhecer a realidade da escola onde os futuros professores irão exercer a sua profissão. $\mathrm{O}$ autor defende que não deve haver distância entre a universidade e a complexidade das escolas, afinal a escola constitui um lugar de aprendizagem e não de aplicação do que foi estudado na universidade.

Sobre isso Ghedin e Franco (2008, p. 36-37) destacaram que as instituições de formação de professores deveriam considerar a 
aproximação entre o espaço de formação e os contextos reais de exercício profissional, precisa se basear em um novo relacionamento no qual as escolas sejam consideradas espaços de aprendizagem profissional e não simples espaços de aplicação. (GHEDIN; FRANCO, 2008, p. 36-37).

A perspectiva de formação de professores para a justiça social, outro aspecto defendido por Zeichner (2011), considera fundamental a integração de professores experientes do nível básico com o ensino do campus, isso significa incluir as equipes do ensino básico e representantes das comunidades, como parceiras a tempo integral, em todos os aspectos do planejamento e renovação dos programas de formação de professores, além da mediação cuidadosa do ensino no campus, em relação à complexidade das escolas.

Há um elemento novo e importante que Zeichner (2011) coloca que é o envolvimento das comunidades no planejamento e renovação dos programas de formação. Concorda-se com esta ideia, pois os professores que são formados têm como missão servir a essas comunidades. Infelizmente, as decisões sobre as reformas são tomadas ao nível mais alto sem, por vezes, se considerar a realidade na qual os professores irão trabalhar.

Ainda no que concerne à formação, Zeichner (2011) coloca a pesquisa-ação que envolve os acadêmicos, professores da escola básica e alunos em formação, como um elemento fundamental nos processos de formação de professores. Este considera importante o projeto coletivo na formação de professores.

Dando a devida importância do trabalho coletivo na pesquisa-ação, Geraldi (1998, p. 259) descreve da seguinte forma:

Outra questão que Zeichner considera importante na pesquisa-ação é a sua execução em grupo, primeiro para superar a tendência individualista, já mencionada anteriormente, e principalmente porque é no grupo e através dele que os professores podem apoiar e sustentar o crescimento uns dos outros. (...) O grupo oferece a vantagem de os professores poderem apoiar-se e contribuir para o conhecimento uns dos outros. Além disso, os professores vêm que os seus problemas não são só seus e têm relação com os dos outros professores ou com a estrutura das escolas e os sistemas educacionais. 
Também se considera que o trabalho coletivo é um aspeto importante no desenvolvimento profissional e institucional, como é o caso das pesquisas em rede e o trabalho colaborativo em rede. $\mathrm{O}$ desenvolvimento individual não consegue trazer transformação da situação num determinado contexto, mas a perspectiva do coletivo, como descreve Nóvoa (2010) e Pimenta (2002), pode alterar uma realidade. Assim destaca-se a importância do trabalho coletivo em todas as instâncias.

Nóvoa (2010, p. 23) voltando-se para os programas de formação contínua, argumenta que se tem revelado ineficazes, coloca como saída "o investimento na construção de redes de trabalho coletivo, que sejam o suporte de práticas de formação, baseadas na partilha e no diálogo profissional". Isso destaca novamente a importância da pesquisa colaborativa em rede, bem como do trabalho coletivo.

Ao finalizar essa argumentação, destacar-se alguns princípios/orientações, que os três autores consideram fundamentais na formação de professores:

- Assumir a indissociabilidade entre a teoria e a prática (PIMENTA, 2002);

- Aceitar o enquadramento dos professores experientes na formação dos mais novos (NÓVOA, 2009, 2010; ZEICNHER, 2011);

- Promover uma formação centrada nas práticas e na análise das práticas (NÓVOA, 2009);

- Envolver professores da universidade, alunos em formação e professores da escola básica em pesquisa-ação (ZEICNHER, 2011);

- Assumir a pesquisa como eixo de formação (PIMENTA, 2002);

- Conceber a formação de professores baseada na investigação que tenha como problemática a acção docente e o trabalho escolar (NÓVOA, 2010);

- Incluir o trabalho coletivo nos processos formativos (NÓVOA, 2010, ZEICNHER, 2011, PIMENTA, 2002). 
A seguir, a partir de análise coletiva com o grupo da pesquisa em rede, apresentam-se algumas aproximações entre alguns princípios que orientam a formação de professores na Universidade Pedagógica/Moçambique, a partir dos autores que orientam esta reflexão. Há que salientar que os princípios referenciados anteriormente não devem ser tomados isoladamente, pois existe uma articulação entre eles.

\section{Estudos em redes colaborativas: aproximações entre os princípios da formação de professores na UP/Moçambique}

Para a abordagem sobre alguns princípios que orientam a formação de professores na UP e as aproximações que existem com os princípios delineados pelos autores supramencionados, é importante se fazer referência ao modelo curricular adotado pela instituição. Julga-se que os princípios não se dissociam do modelo que hoje sustenta sua formaçãod e professores.

A Formação de Professores na Universidade Pedagógica de Moçambique orienta-se por um modelo integrado, constituído por três componentes: Formação Geral (CFG) - 10\%; Formação Educacional (CFEd) -25\%; Formação Específica (CFE) - 65\%. Existe uma combinação de todos os componentes citados, desde o $1^{\circ}$ ano do curso. As práticas profissionalizantes constituem a espinha dorsal da formação, pois iniciam a partir do $1^{\circ}$ ano. No entanto, Ribeiro (1993) alerta que não basta fazer constar os diferentes componentes sem estabelecer a sua articulação. Ele escreve:

Importa, no entanto, acentuar a existência de modos e graus diferentes relativamente à integração das componentes de formação. Em rigor, a simples justaposição temporal de componentes ao longo de programas de formação, sem cuidar da sua articulação, não merece, efetivamente, ser considerada como forma de integração curricular. A integração efetiva das componentes requer 
que o programa seja desenhado e concretizado em torno de vetores programáticos que se reforçam mutuamente e que suportam os diferentes tipos de formação a considerar no programa: a formação geral e científica define-se no contexto da formação profissional do professor e esta não se concretiza sem aquela; a prática também não surge desligada da teoria que a fundamenta e esta não se analisa e esclarece sem aquela (RIBEIRO, 1993, p. 20-21)

A citação de Ribeiro mostra que o desafio não está em fazer constar esses componentes, ao longo do programa, mas sim, conseguir-se realizar uma articulação coerente. Considera-se que para essa articulação deve haver diálogo entre os diferentes docentes que trabalham num determinado curso, além de efetivara um trabalho colaborativo, em que todos lutam para o desenvolvimento institucional, mas também dos professores em formação.

Os princípios que orientam a formação de professores na UP constam do documento intitulado "Bases e Diretrizes Curriculares da Universidade Pedagógica (BDCs)”.

As Bases e Directrizes Curriculares da UP, abreviadamente designada por BDC, definem os princípios gerais em que devem assentar a formação de professores e de outros técnicos e estabelecem Directrizes Curriculares gerais que devem ser seguidas por todos os cursos da UP. As BDC visam elevar a qualidade do ensino, da aprendizagem, da pesquisa, da extensão e da gestão acadêmica e administrativa nos cursos de graduação da UP. (UP, 2008, p. 20-21).

É a partir deste documento que se selecionaram alguns princípios com o objetivo de identificar as aproximações, conforme objetivo inicial. Também se recorreu ao Regulamento Acadêmico, pois ajuda a entender alguns princípios postos na formação docente da UP. 
Quadro 1. Princípios sobre formação - Algumas aproximações dos autores

\begin{tabular}{|c|c|}
\hline $\begin{array}{l}\text { Princípios identificados nas } \\
\text { leituras de Nóvoa, Zeichner e } \\
\text { Pimenta. }\end{array}$ & $\begin{array}{l}\text { Alguns Princípios que orientam a formação na } \\
\text { Universidade Pedagógica de Moçambique (UP) }\end{array}$ \\
\hline $\begin{array}{l}\text { Relação dialética entre a teoria e a } \\
\text { prática (PIMENTA, 2002) }\end{array}$ & $\begin{array}{l}\text { "devem ser garantidas as condições curriculares } \\
\text { para a articulação e a indissociabilidade adequada } \\
\text { entre a teoria e a prática" ( BDC, cap.II, artigo 6) }\end{array}$ \\
\hline $\begin{array}{l}\text { Passar a formação de professores para } \\
\text { dentro da formação através de } \\
\text { enquadramento dos professores } \\
\text { experientes na formação dos mais } \\
\text { novos (NÓVOA, 2009, 2010 e } \\
\text { ZEICNHER, 2011) } \\
\end{array}$ & \multirow{2}{*}{\begin{tabular}{|} 
"Um dos princípios curriculares fundamentais deve \\
ser o da profissionalização que significa o \\
reconhecimento de que deve ser dada na UP uma \\
formação específica para o exercício de uma certa \\
profissão" ( BDC, Cap.II, artigo 6) \\
\\
As Práticas profissionalizantes têm como objetivo : \\
"Desenvolver capacidades de análise e contribuição \\
crítica e criadora para a melhoria da qualidade de \\
ensino-aprendizagem (...); possibilitar a vivencia do \\
meio escolar ou profissional, em contato real ou \\
simulado como os diversos intervenientes, de modo a \\
criar hábitos de colaboração e de convivência, \\
próprios do meio em que se encontra; permitir a \\
adaptação psicológica e sócio-profissional do \\
estudante à sua futura actvidade" (UP, 2008, p. 38)
\end{tabular}} \\
\hline $\begin{array}{l}\text { Formação centrada nas práticas e na } \\
\text { análise das práticas (NÓVOA. 2009) }\end{array}$ & \\
\hline $\begin{array}{l}\text { Pesquisa-ação em equipas que } \\
\text { envolve professores da universidade, } \\
\text { alunos em formação e professores da } \\
\text { escola básica (ZEICNHER, 2011). }\end{array}$ & Não encontrado \\
\hline $\begin{array}{l}\text { Pesquisa como eixo de formação } \\
\text { (PIMENTA, 2002). }\end{array}$ & $\begin{array}{l}\text { Julga-se que a questão da pesquisa está subjacente } \\
\text { naquilo que são as tarefas da Universidade. Pois } \\
\text { esta tem como funções principais a ensino, pesquisa } \\
\text { e extensão. }\end{array}$ \\
\hline $\begin{array}{l}\text { Conceber a formação de professores } \\
\text { baseada na investigação que tenha } \\
\text { como problemática a ação docente e } \\
\text { o trabalho escolar (NÓVOA, 2010). }\end{array}$ & Não encontrado \\
\hline $\begin{array}{l}\text { Incluir o trabalho coletivo nos } \\
\text { processos formativos (NÓVOA, 2010; } \\
\text { ZEICNHER, 2011; PIMENTA, 2002). }\end{array}$ & $\begin{array}{l}\text { O conhecimento científico na UP tem de ser } \\
\text { construído e transformado de forma colectiva, } \\
\text { pautando-se pela socialização e democratização do } \\
\text { saber. }\end{array}$ \\
\hline $\begin{array}{c}\text { Formação para a Justiça social } \\
\text { (ZEICNHER, 2011). }\end{array}$ & $\begin{array}{l}\text { A proposta curricular dos cursos da UP deve ter em } \\
\text { consideração a interculturalidade que significa o } \\
\text { combate a todos os tipos de discriminação e } \\
\text { preconceito, quer sejam rácicos, religiosos, culturais, } \\
\text { étnicos, linguísticos ou sociais . }\end{array}$ \\
\hline
\end{tabular}

Fonte: elaborado pela autora. 
A partir da leitura do quadro 1, verifica-se que o programa de formação de professores na UP, não se distancia muito, em alguns aspectos, das ideias dos autores que orientam a reflexão aqui construída. No programa de formação preconizam-se práticas profissionalizantes; indissociabilidade entre a teoria e a prática, trabalho coletivo, como elemento importante no desenvolvimento profissional, integração de saberes e desenvolvimento profissional, como um ato contínuo e valorização da interculturalidade.

Entretanto, apesar do descritoe assumido como princípios, importa ainda salientar que a UP optou por uma formação de professores baseada em competências. Esse fato cria uma certa dúvida e ambiguidade na interpretação que pode ser dada por diferentes intervenientes no processo. E ainda, pode-se perceber que há um hibridismo no rol de princípios que orientam a formação.

Na leitura das Bases e Directrizes Curriculares da UP, observam-se princípios que orientam a formação de professores aliada ao conceito de competência, para a articulação da teoria e prática, como se pode ler:

A formação profissional conduz-nos a selecção do conceito de "competência" como sendo uma categoria básica que vai permitir a articulação entre a teoria com a prática, assumindo que toda a teoria tem implicações práticas e que toda a prática tem consigo uma teoria (UP, 2008, p. 24)

Nesse sentido, buscou-se entender como os autores que servem de referência neste trabalho se posicionam no que concerne a políticas de formação baseados em competências e como interpretam essa articulação entre a teoria e prática. Nos estudos coletivos em rede, verificou-se que, por exemplo, Pimenta (2002) não se identifica com essa política, pois considera que o conceito de competência surge no âmbito das políticas neoliberais, passando a influenciar as reformas em vários programas de formação de professores no Brasil e no mundo (MAGALHÃES; FORTUNATO; MENA, 2020a).

Como afirma a autora, isso conduziu a uma desvalorização da profissão docente, pois trata-se de uma política que coloca no trabalhador a 
responsabilidade de estar procurando continuamente novas competências, favorecendo, desse modo, o mercado de formação.

Pimenta ainda adverte que o conceito de competências "está substituindo o de saberes e conhecimentos (no caso de educação) e o de qualificação (no caso de trabalho)" (PIMENTA, 2002, p. 41). Ela acrescenta ainda que o discurso sobre competências anuncia um novo (neo)tecnicismo, entendido como um aperfeiçoamento do positivismo caracterizado por controle e avaliação (MAGALHÃES, 2019b).

Quanto a referência da articulação entre a teoria e prática num currículo por competências, Pimenta (2002) aponta que

[...] o termo também significa teoria e prática para fazer algo; conhecimento em situação. O que é necessário para qualquer trabalhador (e também para o professor). Mas ter competência é diferente de ter conhecimento e informação sobre o trabalho, sobre aquilo que se faz (visão de totalidade: consciência ampla das raízes, dos desdobramentos e implicações do que se faz para além da situação; das origens; dos porquês e dos para quê). Portanto, competência pode significar ação imediata, refinamento do individual e ausência do político (...). Os saberes são mais amplos, permitindo que se critique, avalie e supere as competências (PIMENTA, 2002, p. 41).

Percebe-se que o modelo de competências está direccionado fundamentalmente ao saber-fazer, portanto sustentado por uma epistemologia da prática (SOUZA; MAGALHÃES, 2017a; 2017b). A análçise empreendida mostra que a articulação teoria e prática evocada nas Bases e Directrizes Curriculares da UP, não pode ser tomada como práxis.

Considera-se que apesar de ter havido influência das políticas neoliberais, o programa de formação UP preconiza alguns aspectos, que se julgam fundamentais na formação docente, como foi apontado anteriormente. Entretanto, há que destacar que nem tudo o que é definido é aplicado conforme o preconizado.

Um dos princípios apontados por Nóvoa $(2009 ; 2010)$ é a formação de professores dentro da profissão e a formação centrada nas práticas e análise das práticas. No caso da UP se concretiza o solicitado por Nóvoa por meio de práticas 
pedagógicas. No entanto, esse é um dos aspetos que tem trazido problemas na sua implementação, conforme apontou Buque (2012, p. 34), nos seguintes termos

Os docentes da UP não conseguem fazer um acompanhamento adequado aos praticantes devido ao número excessivo destes. $\mathrm{O}$ estudante praticante, segundo o Regulamento Acadêmico, no seu artigo 9, é o discente da UP que realiza Práticas Pedagógicas numa escola. Em que as suas principais tarefas são: Observar a realidade escolar no seu conjunto; observar aulas do tutor e dos seus colegas da UP; Planificar aulas e lecionar; Observar conselhos de notas; participar em todas as atividades escolares, tais como reunião dos grupos de disciplina, reuniões de turmas, reunião com os pais e encarregados de educação (UP, 2005).

(...) Por vezes, um único docente tem que acompanhar mais de 20 alunos que estão em diferentes escolas e distantes umas das outras (UP, 2005).

(...) O que geralmente acontece é que, quando os praticantes chegam às escolas, alguns professores os abandonam à sua sorte (UP, 2005).

A citação expressa a dificuldade de realizar as práticas na escola, o que também é apontado por Duarte (1996) ao afirmar que apesar de se considerar que as práticas pedagógicas (PPs) trouxeram mudanças substanciais na qualidade de formação de futuros professores, também tem alguns constrangimentos, como: a dificuldade em articular com as escolas, a dificuldade em enquadrar as PPs nos horários, a falta de formação de tutores $^{4}$ e supervisores (supervisor é docente da UP que acompanha o estudante praticante), a sobrecarga dos docentes da UP, elevado número de estudantes por turma e falta de transporte para a deslocação dos praticantes e dos supervisores. Uma das soluções que se apontam é a existência de um memorando de entendimento entre o MEC e a UP, no sentido de existirem escolas já pré-determinadas para recepção dos praticantes.

\footnotetext{
${ }^{4}$ Tutor é o professor que apoia a integração do estudante na vida escolar (Duarte, 1996).
} 
Até aqui pode-se dizer que as limitações supramencionadas evidenciam que nos processos de formação da UP existem fatores internos e externos que influenciam. Como na maioria das instituições de formação de professores no Brasil e em Moçambique, a UP constitui um campo de tensões e contradições.

\section{Algumas considerações}

A reflexão realizada neste artigo teve como objetivo identificar e compreender alguns princípios que permeiam a formação de professores na fase contemporânea, buscando encontrar possíveis aproximações com os princípios que orientam a formação na UP. Verifica-se que existem algumas aproximações conforme exposto no Quadro 1, mas também se nota alguns aspetos divergentes, como é o caso da formação estar baseada em competências, política que não é defendida pelos autores aqui priorizados.

Ainda pode-se destacar que existem princípios semelhantes no contexto do documento - Bases e Directrizes Curriculares da UP, no entanto, como foi apresentado, nem tudo o que é definido no documento é aplicado, conforme o preconizado. Isso indica que sob a influência das políticas neoliberais, o programa de formação UP passa a preconizar aspectos que se julgam fundamentais na formação docente, como direcioná-la a aquisão de competências, distanciando os principios da formação daqueles que a consolidariam como práxis.

Com os estudos e análises desenvolvidos com o grupo da pesquisa em Rede, entende-se que o grande desafio não é o fazer constar ou não um determinado princípio no programa de formação da UP, mas sim a sua interpretação, bem como a criação de um ambiente adequado para seu desenvolvimento e, sobretudo ajudar a consolidar uma concepção de educação crítica e emancipadora entre os professores, os quais a defenderão no contexto de sua futura atuação profissional. 


\section{REFERÊNCIAS}

CONTRERAS, J. Autonomia dos professores. São Paulo: Cortez, 2003.

DUARTE, N. A escola de Vigotski e a educação escolar: algumas hipóteses para uma leitura pedagógica da psicologia histórico-cultural. Psicologia USP, v. 7, n. $1-2$, p. 17-50, 1996 .

GERALDI, C. M. G.; FIORENTINI, D.; PEREIRA, E. M.de A. Refletindo com Zeichner: um encontro orientado por preocupações políticas, teóricas e epistemológicas. In: GERALDI, C. M. G.; FIORENTINI, D.; PEREIRA, E. M. de A. Cartografias do trabalho docente. Campinas-SP: Mercado de letras. 1998.

GHEDIN, E. L.; FRANCO, M. A. S. Questões de método na construção da pesquisa em educação. São Paulo: Cortez, 2008. (Col. Docência em Formação. Série Saberes Pedagógicos).

LISTON, D. P. ZEICHNER, K. M. Formación del profesorado y condiciones sociales de la escolarización. 3 ed. Tradução: Pablo Manzano. Madrid: Morata, 2003. Col. Educacion Crítica.

MAGALHÃES, S. M. O. Epistemologia da práxis: enfoque emancipatório e contra hegemônico na produção acadêmica. Revista Intersaberes, vol. 13, n. 30, 2019a.

MAGALHÃES, S. M. O. Violência política e ideológica contra os professores: a pedagogia do oprimido como medida de intervenção e transformação. International Journal of Latest Research in Humanities and Social Science (IJLRHSS). Volume 02. pp. 01-05- Issue 02, 2019b.

MAGALHÃES, S. M. O.; ARAUJO, S. M.; ARGÜELLO, S. B. Agudización ultra neoliberal, educación Y formación docente em Brasil Y Argentina. Revista Interação, Goiânia, v. 45, n. 1, p. 49-80, jan/abr, 2020 b.

MAGALHÃES, S. M. O.; FORTUNATO, I.; MENA, J. La universidad como resistencia: en busca de una epistemología de la práxis. Rev. HISTEDBR On-line. Campinas, SP v. 20 1-14 e 020001, 2020a.

NÓVOA, A. O regresso dos professores. Educa, Lisboa, Portugal, 2010.

NÓVOA, A. Professores: imagens do futuro presente. Lisboa: Educa, 2009.

PIMENTA, S. G. Professor Reflexivo: construindo uma crítica. In: PIMENTA, S. G. (Org.) Professor reflexivo no Brasil: gênese e crítica de um conceito. São Paulo: Cortez, 2002. p. 17-52.

RIBEIRO, A. C. Formar professores. Elementos para uma teoria e prática de formação. Lisboa, Texto Editora, 1993. 
SACRISTÁN, J. G. Poderes instáveis em educação. Porto Alegre: Artmed, 1999.

SANTOS, M. F. P. O Estágio enquanto espaço de pesquisa: Caminhos percorridos na formação docente em Geografia. Tese de Doutorado. UFRGS. Porto Alegre: 2012.

SCHÖN, D. Educando o profissional reflexivo - um novo design para o ensino e a aprendizagem. Porto Alegre: Artes Médicas, 2000. (Prefácio e Parte I, caps. I e II). p. 12-42.

SILVA, K. A. C. P. C. da. A formação de professores na perspectiva crítico emancipadora. Revista Linhas Críticas, Brasília, DF, v. 17, n. 32, p. 13-31, jan./abr. 2011.

SOUZA, R. C. C. R. de. Ribeiro de Novos paradigmas: pontes entre o mal-estar e o bem estar Docente, In: Linhas Críticas, Brasília, DF, n. 36, p. 433-453, maio/ago. 2012.

SOUZA, R. C. C. R de.; MAGALHÃES, S. M. O. Epistemologia da práxis e a produção do conhecimento. Revista de Educação Pública, v. 27, n. 64, p. 17-40, 2017a.

SOUZA, R. C. C. R. de; MAGALHÃES, S. M. O. Epistemologia da práxis e a produção do conhecimento. Revista de Educação Pública, [S. 1.], v. 27, n. 64, p. 17-40, 2017b.

UNIVERSIDADE PEDAGÓGICA (UP). Bases e Directrizes Curriculares para os cursos de Graduação da Universidade Pedagógica. Moçambique. Maputo, 2008. UNIVERSIDADE PEDAGÓGICA (UP). Regulamento acadêmico para os cursos de Graduação e de Mestrado. Moçambique. Maputo, 2010.

ZEICHNER, K. Para além da divisão entre professor-pesquisador e professor acadêmico. In: GERALDI, C. M. G.; FIORENTINI, D.; PEREIRA, E. M.de A. Cartografias do trabalho docente. Campinas-SP: Mercado de letras. 1998.

ZEICHNER, K.; FLESSNER, R. Educando os professores para a educação crítica. In: APLE, M. W.; AU, W.; GANDIN, L. A. Educação Crítica-Análise internacional. Artmed, 2011. p. 331-348 